\title{
$\left.{ }^{14} \mathrm{C}\right] \mathrm{Bicarbonate}$ fixation into glucose and other metabolites in the liver of the starved rat under halothane anaesthesia
}

\author{
Metabolic channelling of mitochondrial oxaloacetate
}

\author{
Dennis F. HEATH and John G. ROSE \\ MRC Trauma Unit, Medical School, University of Manchester, Oxford Road, Manchester M13 9PT, U.K.
}

(Received 12 October 1984/27 December 1984; accepted 10 January 1985)

\begin{abstract}
1. Previous attempts to account for the labelling in vivo of liver metabolites associated with the citrate cycle and gluconeogenesis have foundered because proper allowance was not made for the heterogeneity of the liver. In the basal state (anaesthetized after $24 \mathrm{~h}$ starvation) this heterogeneity is minimal, and we show that labelling by $\left[{ }^{14} \mathrm{C}\right]$ bicarbonate can be interpreted unambiguously. $2 .\left[{ }^{14} \mathrm{C}\right] \mathrm{Bicarbonate}$ was infused to an isotopic steady state, and measurements were made of specific radioactivities of blood bicarbonate, alanine, glycerol and lactate, of liver alanine and lactate, and of individual carbon atoms in blood glucose and liver aspartate, citrate and malate. (Existing methods for several of these measurements were extensively modified.) The results were combined with published rates of gluconeogenesis, uptake of gluconeogenic precursors by the liver, and citrate-cycle flux, all measured under similar conditions, and with estimates of other rates made from published data. To interpret the results, three ancillary measurements were made: (i) the rate of $\mathrm{CO}_{2}$ exchange by phosphoenolpyruvate carboxykinase (PEPCK; EC 4.1.1.32) under conditions that simulated those in vivo; (ii) the ${ }^{14} \mathrm{C}$ isotope effect in the pyruvate carboxylase (EC 6.4.1.1) reaction $\left({ }^{14} \mathrm{C} /{ }^{12} \mathrm{C}=0.992 \pm 0.008\right.$; S.E.M., $n=8$ ); (iii) the ratio of labelling by $\left[2-{ }^{14} \mathrm{C}\right]$ - to that by $\left[1-{ }^{14} \mathrm{C}\right]$-pyruvate of liver glutamate $1.5 \mathrm{~min}$ after injection. This ratio, 3.38, is a measure of the disequilibrium in the mitochondria between malate and oxaloacetate. 3. The data were analysed with due regard to experimental variance, uncertainties in values of fluxes measured in vitro, hepatic heterogeneity and renal glucose output. The following conclusions were reached. (i) The results could not be explained if $\mathrm{CO}_{2}$ fixation was confined to pyruvate carboxylase and there was only one, well-mixed, pool of oxaloacetate in the mitochondria. (ii) Addition of the other carboxylation reactions, those of PEPCK, isocitrate dehydrogenase (EC 1.1.1.42) and malic enzyme (EC 1.1.1.40), was not enough. Incomplete mixing of mitochondrial oxaloacetate had to be assumed, i.e. that there was metabolic channelling of oxaloacetate formed from pyruvate towards gluconeogenesis. (iii) There was some evidence that malate exchange across the mitochondrial membrane might also be channelled, with incomplete mixing with that in the citrate cycle. (iv) Calculated rates of exchange of $\mathrm{CO}_{2}$ by PEPCK were in agreement with those measured in vitro, with little or no activation by $\mathrm{Fe}^{2+}$ ions. (v) Provided that there was a small net output of glutamine from the liver, as expected in the starved rat, calculated values of the mitochondrial/cytosolic [malate] ratio accorded with published measurements in vitro.
\end{abstract}

The hepatic metabolism of carbohydrate and fat is highly dependent on the metabolic state, and changes can only be understood from a knowledge of the rates of flow along and the interactions be- tween the different metabolic pathways. For reasons given below, a true picture in vivo cannot be got from studies of isolated systems.

The usual approach in vivo involves administra- 
tion of labelled substrates and measurement of the incorporation of label into other metabolites. There are considerable practical and theoretical difficulties in interpreting the results of such studies; and the main aim of this paper is to show that under favourable circumstances they can be overcome. In so doing some interesting features of metabolism have been uncovered.

The difficulties have four main sources. (1) The liver is cellularly heterogeneous. In the parenchyma there are gluconeogenic, glycolytic and intermediate-type cells that co-exist in proportions that change with nutrition (Jungermann \& Sasse, 1978). (2) Within cells, compounds not only are compartmented into mitochondrial and extramitochondrial (cytosolic) pools, but within each pool may be channelled along specific pathways (Clegg, 1984). This is the mathematical equivalent of sub-compartmentation, even though there are no boundary membranes. (3) The balance between the portal and arterial blood supplies is so delicate (Mendell \& Hollenberg, 1971; Sasaki \& Wagner, 1971) that the net rates of uptake and output of substrates cannot be measured reliably except under anaesthesia, and this itself alters metabolism. (4) In vivo it is harder than in vitro to achieve reproducible labelling, take specimens for analysis and assess the interactions with the rest of the system. Consequently there are too many parameters to measure in a single experiment.

The first two factors above cast doubt on the validity of any conclusions drawn from measurements made on specimens taken from the whole liver, whether in situ or isolated and perfused, and since their likely effects were appreciated there has been a tendency for biochemists to turn to hepatocytes as providing simpler and more controllable systems. There are, however, fundamental objections to treating findings in hepatocytes as reliably indicative of processes in vivo, although they may set limits on what can be made to happen. Not only are hepatocytes in a different environment; substrate and hormonal mixtures are usually un-

Abbreviations used: $\mathrm{MDH}$, malate dehydrogenase (EC 1.1.1.37); fumarase, fumarate hydratase (EC 4.2.1.2); LDH, lactate dehydrogenase (EC 1.1.1.27); GPT, glutamate-pyruvate transaminase (EC 2.6.1.2); PEPCK, phosphoenolpyruvate carboxykinase (EC 4.1.1.32); PEP, phosphoenolpyruvate. Positions labelled by ${ }^{14} \mathrm{C}$ and their specific radioactivities (S.R.s) are both denoted by ' $C$ ' followed by the position(s) labelled, e.g. $\mathrm{C} 2$-pyruvate is $[2-14 \mathrm{C}]$ pyruvate, and the $\mathrm{C} 3 / \mathrm{C} 2$ ratio in glutamate is the ratio of the S.R.s of C-3 and C-2 in glutamate. Labelling in the $\mathrm{Cl}$ and $\mathrm{C} 6$ positions in citrate was measured as (and mostly derived from) that in the $\mathrm{C} 4$ and $\mathrm{Cl}$ positions in malate. To simplify presentation the $\mathrm{Cl}$ and $\mathrm{C} 6$ positions in citrate are referred to as $\mathrm{C}(\mathrm{M} 4)$ and $\mathrm{C}(\mathrm{M} 1)$ respectively. physiological, there is no equivalent of the dual blood supply of the liver, and there is no innervation.

We therefore set out to explore the possibility of modelling the relevant pathways in vivo under the most controllable conditions we could contrive, i.e. infusion of $\left[{ }^{14} \mathrm{C}\right]$ bicarbonate to a steady isotopic state into the rat in the basal state, induced by halothane anaesthesia and 24h starvation (Denckla, 1970; Heath \& Rose, 1976). This system provided an additional challenge, because it was closely analogous to one of those used in a thorough kinetic study of hepatocytes by Müllhofer $e t$ al. $(1977 a, b)$, who could not account for their findings with this substrate by accepted pathways.

Besides its intrinsic interest, the work was also carried out to provide a baseline for studies of other metabolic states, especially that shortly after injury, when the liver does not respond normally to the high circulating concentrations of glucose and insulin (Heath, 1981). Since these phenomena do not carry over into isolated preparations, they can only be studied in vivo.

The system chosen for study is optimal for a number of reasons. (1) In the basal state most cells are gluconeogenic, and cellular heterogeneity is at a minimum (Sasse et al., 1975), as is liver glycogen (Higgins et al., 1932; Goldstein \& Curnow, 1973). (2) Since the rats were anaesthetized, published measurements on starved anaesthetized rats could be safely used to fill out our own data. $(3)\left[{ }^{14} \mathrm{C}\right] \mathrm{Bi}$ carbonate gives the particularly simple pattern of labelling shown in Scheme 1. (This merely outlines the relationships between the labelling of key compounds, and is not a kinetic model.) The only positions labelled are C3,4 in glucose, $\mathrm{C} 1,4$ in aspartate, malate and oxaloacetate, $\mathrm{Cl}, 6$ in citrate, and $\mathrm{Cl}$ in $\mathrm{C}_{3}$ compounds. Other positions may become labelled via the pentose phosphate pathway, but measurement showed that there was very little such labelling. The substrate should only label parenchymal cells, since non-parenchymal cells lack the enzymes for $\mathrm{CO}_{2}$ fixation (Crisp \& Pogson, 1972). (4) Infusion to a steady state simplifies mathematical analysis. There is then, however, appreciable return of label via glycerol and the Cori and alanine cycles, so that the S.R.s of blood glycerol, lactate and alanine had to be measured for the effects of recycling to be assessed.

The S.R.s measured in the liver were those of alanine, aspartate, citrate, glucose, lactate and malate, and those of individual carbons in all but alanine and lactate. These did not provide enough data to measure all the parameters. In part the deficiency was supplied by published measurements. We could, however, find no measurements of the ${ }^{14} \mathrm{C}$ isotope effect in the pyruvate carboxylase reaction or of $\mathrm{CO}_{2}$ fixation by PEPCK under condi- 


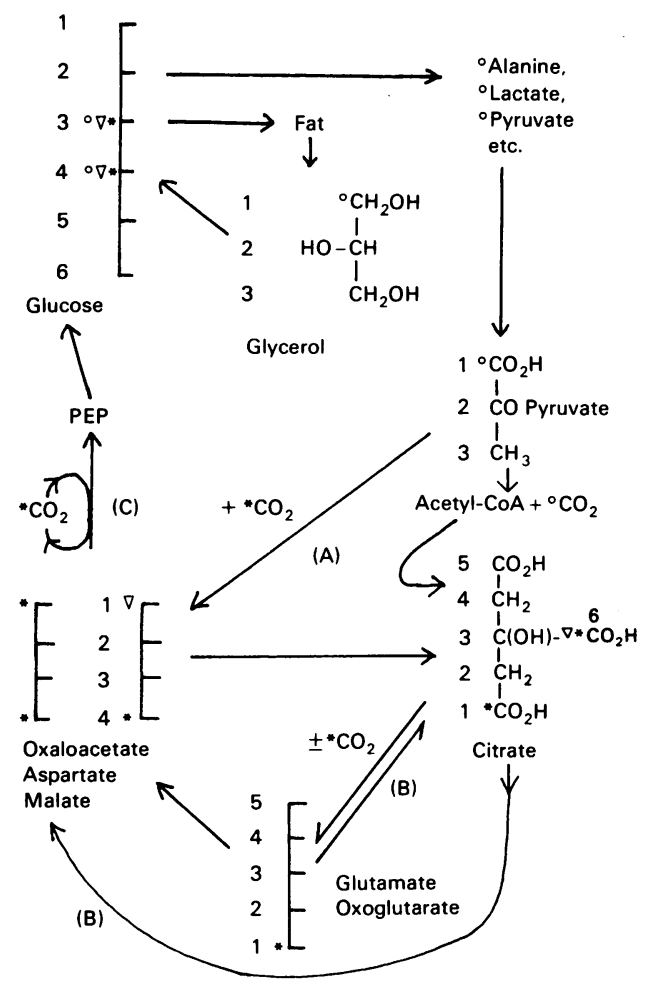

Scheme 1. Pathways of incorporation of $\left[{ }^{14} \mathrm{C}\right]$ bicarbonate label into liver metabolites

Label is incorporated directly by reactions: (A), pyruvate carboxylase (EC 6.4.1.1) and malic enzyme (EC 1.1.1.40); (B), exchange on isocitrate dehydrogenase (EC 1.1.1.42), followed by conversion of citrate into oxaloacetate by citrate lyase (EC 4.1.3.6); (C), and exchange on PEPCK. The positions initially labelled are denoted by asterisks. Label that has been transferred from the $\mathrm{C} 4$ to the $\mathrm{Cl}$ positions in malate and oxaloacetate by the action of mitochondrial fumarase is denoted by $\nabla$. Label that re-enters the system via conversion of glucose into alanine, glycerol, lactate and other metabolites is denoted by $\mathrm{O}$ as far as acetyl-CoA and $\mathrm{CO}_{2}$ formation, but is otherwise omitted, since it follows the same pattern as that denoted by $\nabla$.

tions like those in vivo, and we have therefore done them ourselves. The ratio of the S.R.s of liver glutamate at short times after injection of $\mathrm{C2}$ - and $\mathrm{Cl}$ pyruvate was also measured to determine the disequilibrium between mitochondrial fumarate and oxaloacetate. The theory is given in the Appendix.

Most measurements gave only ranges within which values of rates etc. were likely to lie. Our conclusions were therefore checked by extensive simulation studies to show that they did not depend on a choice of particular combinations of parameter values, and to see how they were affected by variance in our data, assumptions about heterogeneity etc.

It was necessary to improve published methods for measuring the S.R.s of most of the compounds studied, otherwise systematic errors grossly exceeded the biological variance (5000 times more in one case). Those for alanine, citrate, lactate and malate are given here; references to the others are cited in the Materials and methods section.

\section{Materials and methods}

Unless stated otherwise, results are given as means \pm S.E.M. for the numbers of experiments given in parentheses.

\section{Chemicals and instrumentation}

Radiochemicals were bought from The Radiochemical Centre, Amersham, Bucks., U.K.; malic enzyme (EC 1.1.1.40) was from Sigma (London) Chemical Co., Poole, Dorset, U.K.; other enzymes were from Boehringer Corp. (London), Lewes, Sussex, U.K.; and ion-exchange resins (AR grade) were from Bio-Rad Laboratories, Richmond, CA, U.S.A.

C1-Malate was prepared from C1-pyruvate with malic enzyme and glucose-6-phosphate dehydrogenase (EC 1.1.1.49) essentially as described by Ochoa et al. (1950). C4-Malate and $\left[{ }^{3} \mathrm{H}\right]$ malate were prepared from labelled aspartate, C2-lactate and $\left[{ }^{3} \mathrm{H}\right]$ lactate from labelled alanine, and labelled citrate was prepared from labelled malate by standard enzymic methods (Bergmeyer, 1974). Methods of separation are described below.

PEPCK was prepared from the livers of six rats starved for $24 \mathrm{~h}$ as described by Philippidis et al. (1972) up to and including $\left(\mathrm{NH}_{4}\right)_{2} \mathrm{SO}_{4}$ fractionation after DEAE-cellulose chromatography, except that dialysis was omitted. The specific activity was $0.09 \mu \mathrm{kat} / \mathrm{mg}$, measured with $\mathrm{Mn}^{2+}$ catalysis in the direction of PEP formation (Ballard \& Hanson, 1969). The preparation was stable for 2 months.

Pyruvate carboxylase was prepared from the livers of six rats starved for $24 \mathrm{~h}$, and purified to Stage IV (McClure et al., 1971b). The yield was $2 \mathrm{mg}$ of $0.05 \mu \mathrm{kat} / \mathrm{mg}$. The product was stable for 1 week.

Radioactivities were measured by a Packard scintillation spectrometer. Precision was better than $1 \%$, except for lightly labelled carbons in distribution studies, when it was always better than $0.1 \%$ of total label in the compound studied. Count rates were corrected to constant efficiency by using internal standards. Enzymic measurements were carried out with a Unicam 8-200 spectrophotometer. 


\section{Animal experiments}

Porton-Wistar male rats (body wt. 220-241 g) that had been maintained for at least 3 weeks at $20^{\circ} \mathrm{C}$ ambient with $12 \mathrm{~h}$ light/day were starved for $24 \mathrm{~h}$ before use. Each rat was anaesthetized with halothane, and ambient temperature was adjusted to maintain the colon temperature at $37-38^{\circ} \mathrm{C}$ (Heath \& Rose, 1976). For infusion experiments a cannula was inserted into a lateral tail vein, and another, for blood sampling, into a tail artery (Agrelo \& Dawson, 1968). Infusion with $\left[{ }^{14} \mathrm{C}\right]$ bicarbonate $\left(\mathrm{pH} 7.5,0.2 \mathrm{M}\right.$ in $\left.\mathrm{Na}^{+}, 7-8 \mathrm{MBq} / \mathrm{ml}\right)$ was initially at $0.076 \mathrm{ml} / \mathrm{min}$. The rate was halved at each of 3,15 and $30 \mathrm{~min}$, so that the rat received $1.8 \mathrm{ml}$ in $2 \mathrm{~h}$. Arterial samples $(0.2 \mathrm{ml})$ were taken at 90 and $120 \mathrm{~min}$ for measurement of bicarbonate and glucose and their S.R.s. From some rats a liver specimen was then taken immediately with tongs cooled in liquid $\mathrm{N}_{2}$. From the rest blood $(2 \mathrm{ml})$ was taken slowly (over about $6 \mathrm{~min}$ ) for measurement of blood metabolites, but no liver specimen, since such heavy blood loss affects metabolism (Walsh $e t$ al., 1980). The slowness of changes during the last $30 \mathrm{~min}$ of infusion showed that a steady state had nearly been reached. Blood [bicarbonate] decreased from $27.8 \mu \mathrm{mol} / \mathrm{ml}$ by $0.3 \pm 2.5 \%$ (24) and its S.R. by $2.2 \pm 2.1 \%$ (23), and the S.R. of blood glucose rose by $4.4 \pm 1.3 \%$ (19).

To measure the disequilibrium between oxaloacetate and fumarate in the mitochondria, rats were anaesthetized as above for at least $40 \mathrm{~min}$ to allow the initial excitatory phase to subside. Each rat then received via a tail vein either $\mathrm{C} 1-$ or $\mathrm{C} 2$ pyruvate $\left(10^{7}\right.$ c.p.m. $/ 100 \mathrm{~g}$ body wt. in $0.2 \mathrm{ml}$ of $0.9 \% \mathrm{NaCl}$ per rat), and a liver specimen was taken as above $1.5 \mathrm{~min}$ after injection. Glutamate was separated and its S.R. measured (Heath \& Phillips, 1972).

\section{Preliminary separations (infusion experiments)}

Protein was precipitated from liver and blood specimens with $0.5 \mathrm{M}-\mathrm{HClO}_{4}(6 \mathrm{ml} / \mathrm{g}$ of liver, $2 \mathrm{ml} / \mathrm{ml}$ of blood) containing tritiated markers and small amounts of carriers $(<20 \%$ of the endogenous metabolites). For blood these were alanine and lactate; for the liver, alanine, aspartate, citrate, glutamate, lactate and malate $(2 \mathrm{kBq}$ and $0.02 \mu \mathrm{mol}$ of each). Blanks were obtained by treating specimens of the supplemented $\mathrm{HClO}_{4}$ in the same way as the biological extracts. (The carriers were needed to make 'blank' columns run like those with biological specimens.) Recoveries were calculated from the recoveries of the tritiated markers.

Amino acids were extracted by a column of AG50-X8 resin ( $2 \mathrm{ml} ; 200-400$ mesh; pre-washed with $1 \mathrm{M}-\mathrm{HCl}$ and water). The eluate contained the neutral and acidic compounds, which were separated by passage through AG1-X8 or AG1-X10 resin $\left(\mathrm{Cl}^{-}\right.$form, $200-400 \mathrm{mesh}$; $6 \mathrm{ml}$; bed depth $220 \mathrm{~mm}$; pre-washed with $\mathrm{HCl}$ and water), monitored by measurements of ${ }^{3} \mathrm{H}$. The initial eluate (12 $\mathrm{ml}$ of water) contained the glucose and glycerol, and was concentrated to $0.5 \mathrm{ml}$ by a stream of $\mathrm{N}_{2}$ at $55^{\circ} \mathrm{C}$ before analysis. (All eluates were concentrated in this way.) Lactate, malate and citrate were then eluted in turn, with $5 \mathrm{mM}-\mathrm{HCl}$ (about $40 \mathrm{ml}), 10 \mathrm{mM}-\mathrm{HCl}(25 \mathrm{ml})$ and $50 \mathrm{mM}-\mathrm{HCl}(20 \mathrm{ml})$ respectively. The compounds appeared as sharp peaks, with good separation from succinate and 2oxoglutarate but with incomplete separation of malate and acetate. There were small isotope effects, tritiated compounds giving peaks at $1-2 \mathrm{ml}$ and ${ }^{14} \mathrm{C}$-labelled compounds at about $0.5 \mathrm{ml}$ before the unlabelled compounds, so a small trailing guard fraction was always retained. [The method is derived from that of von Korff (1960). Compounds in the un-neutralized eluates were stable at $4^{\circ} \mathrm{C}$ for several weeks, and were neutralized and concentrated immediately before use. Metabolites in cuvette contents were separated in the same system, when only $25 \mathrm{ml}$ of $5 \mathrm{mM}-\mathrm{HCl}$ was needed to elute lactate.] Amino acids were eluted from the AG50-X8 column with $1 \mathrm{M}-\mathrm{NH}_{3}$, and fractions containing alanine, aspartate and glutamate were separated as described by Heath et al. (1971). The 'alanine' fraction contained all the other neutral amino acids.

\section{Analytical methods}

Further separations and analyses were carried out on the extracts prepared as above, except for blood bicarbonate and its S.R., which were measured as described by Rose (1976), with concomitant preparation of an extract from which glucose could be separated. Purification and measurement of aspartate and glutamate (Heath \& Phillips, 1972), glucose (Frayn, 1976) and glycerol (Rose, 1981) and their S.R.s were carried out as described in the references cited. The purity of glucose after paper chromatography was checked by measuring the S.R. of the leading and trailing halves of the band on the paper. The ratio (S.R. leading)/(S.R. trailing) was $1.011 \pm 0.005$ (8).

The other compounds were separated and converted into lactate or malate for final measurement. Lactate was measured by conversion into alanine with LDH and GPT, and malate by conversion into citrate with $\mathrm{MDH}$ and citrate synthase. Speed and precision were increased by running the assays at pH 10 using 4 times the [NAD ${ }^{+}$] recommended by Bergmeyer (1974). Since no lactate or malate of guaranteed purity for use as standards was available, concentrations were calcu- 
lated from the specific molar absorbance of NADH at $25^{\circ} \mathrm{C}$ and $334 \mathrm{~nm}$ (Bergmeyer, 1975). The validity of the method was checked by measuring the purity of A.R. glucose by a hexokinase method (Bergmeyer, 1974) by using the molar absorbance of NADPH (Bergmeyer, 1975). The value found, $99.34 \pm 0.03 \%$ (12), was very close to the manufacturer's stated $99.5 \%$, measured as dextrose equivalents with copper.

The methods for the individual compounds were as follows. Chloride columns were as described under 'Preliminary separations'.

Lactate. Each specimen was divided into two, and each half was treated as for the measurement of lactate described above, except that LDH was omitted from one. Both were then passed through acetate resin (AG50-X8; acetate form: 200-400 mesh; $3 \mathrm{ml})$ to remove any unchanged lactate $(<1 \%)$ and buffer constituents, which interfered with the measurement of radioactivity. The eluates were concentrated and counted for radioactivity in Instagel. The lactate counts were calculated by difference. The 'blank' count rate was $5-10 \%$ of the lactate count rate.

Alanine. This was converted into lactate (Bergmeyer, 1974), which was separated on a chloride column and then treated as described under 'Lactate'. The conversion into lactate eliminated $45 \%$ of the marker label, and this was allowed for in calculating recoveries.

Malate. This was converted into citrate, separated on a chloride column, re-converted into malate with citrate lyase (Bergmeyer, 1974), and re-separated. Conversion into citrate decreased the S.R. by about $30 \%$. A loss of $8.8 \pm 1.2 \%$ (4) of the marker label during the interconversions was taken into account.

Citrate. This was converted into malate, which was then treated as above, i.e. converted into citrate and back to malate. A single conversion left some labelled impurity (not acetate) equivalent to $10-30 \%$ of the citrate label. [Malate] was measured after the final separation, and a portion counted for radioactivity to measure the S.R.

Specific labelling. (1) Malate and citrate as malate. Malic enzyme and GPT were used to transfer $\mathrm{Cl}$ label to $\mathrm{CO}_{2}$ and the rest to alanine. Fumarase was added to half of each specimen to equalize $\mathrm{Cl}$ and $\mathrm{C} 4$ label, and the $\mathrm{C} 4 / \mathrm{Cl}$ ratio was calculated by comparing the results with and without fumarase addition. Measurements on authentic specifically labelled C1-malate and C4malate were made in parallel. Had the natural malate contained C2,3-label, the alanine fraction separated after fumarase treatment would have contained a higher proportion of the total label than that from the authentic specimens. In detail, eluates from the chloride columns were concen- trated and neutralized. From each a $1 \mathrm{~g}$ portion was placed into each of two scintillation vials $(20 \mathrm{ml})$ with glutamate $/ \mathrm{HCl}$ buffer $(0.4 \mathrm{ml}$ of $0.1 \mathrm{M}, \mathrm{pH} 7.5)$, Tris/ $\mathrm{HCl}$ buffer $(0.3 \mathrm{ml}$ of $0.2 \mathrm{M}, \mathrm{pH} 7.5)$, NADP+ $(0.1 \mathrm{ml}, 4 \mathrm{mg} / \mathrm{ml}), \mathrm{MnCl}_{2}(0.2 \mathrm{ml}, 5 \mathrm{mg} / \mathrm{ml}), \mathrm{GPT}$ $(0.02 \mathrm{ml}, 13 \mu \mathrm{kat} / \mathrm{ml})$, and, to one portion, fumarase $(0.01 \mathrm{ml}, 11 \mu \mathrm{kat} / \mathrm{ml})$. After $30 \mathrm{~min}$ a $\mathrm{CO}_{2}$ trap was placed in each vial (Rose, 1976), malic enzyme ( 0.05 nkat) was added, and the vial closed with a rubber cap. After $1 \mathrm{~h}$ at $25^{\circ} \mathrm{C}, 1 \mathrm{M}-\mathrm{HClO}_{4}(0.8 \mathrm{ml})$ was injected into each vial through the cap, followed by $0.05 \mathrm{M}-\mathrm{NaHCO}_{3}(0.1 \mathrm{ml})$. (The last was needed to ensure complete transfer of $\mathrm{CO}_{2}$ to the trap.) The vials were shaken in a Dubnoff shaker for $1 \mathrm{~h}$ and then left overnight. The trap contents were counted for radioactivity (Rose, 1976). The vial contents were neutralized with $10 \mathrm{M}-\mathrm{KOH}$, and the alanine was separated as described above from buffer constituents. The eluate was concentrated and counted for radioactivity in Instagel scintillant. Reproducibility was better than $2 \%$ (coefficient of deviation, $n=10$ ). Recoveries of $\mathrm{CO}_{2}$ from $\mathrm{Cl}-, \mathrm{C} 4-$ and $\mathrm{C}(\mathrm{U})$-malate were $1.25 \pm 0.02 \%(4)$, $99.2 \pm 0.4 \%$ (4) and $24.0 \pm 0.2 \%$ (4) respectively (theory: $0 \%, 100 \%, 25 \%$ ). There was negligible transfer of label from the $\mathrm{C} 4$ to the $\mathrm{Cl}$ position during separation, as was demonstrated by adding $\mathrm{C} 4$ malate to $\mathrm{HClO}_{4}$ used to extract livers of three rats and then following the whole procedure for malate. Only $0.41 \pm 0.06 \%$ of the label was found in the $\mathrm{Cl}$ position.

In trial runs the initial conversion of citrate into malate and acetate was followed by separation of acetate with carrier and marker. Less than $2 \%$ of the citrate label was in acetate.

(2) Aspartate. Aspartate was measured by conversion into malate. This was separated as above, and the specific labelling measured.

(3) Glucose. C6 label was measured as described by Bloom (1962), by using [6-3 $\mathrm{H}]$ glucose to estimate recoveries. S.R.s measured on C1-, C6and $\mathrm{C}(\mathrm{U})$-glucose as percentages of initial values were $96 \pm 2(3), 1.3 \pm 0.2$ (3) and $16.0 \pm 0.5$ (3), compared with 100,0 and $16.7 \%$ theoretical. $\mathrm{Cl}$ label was measured by the ${ }^{14} \mathrm{CO}_{2}$ released by 6-phosphogluconate dehydrogenase (EC 1.1.1.44) essentially as described by Lange et al. (1972). The reaction time was increased to $3 \mathrm{~h}$ and the ${ }^{14} \mathrm{CO}_{2}$ was collected as from the malic enzyme reaction above. Recoveries were low ( $<80 \%)$ and variable from run to run, although reproducible within a run. Biological specimens were therefore always analysed alongside authentic $\mathrm{Cl}$-glucose so that recoveries could be measured. There was negligible recovery of $\mathrm{C} 6$ label $(<0.1 \%)$.

(4) Glutamate. $\mathrm{Cl}$ and $\mathrm{C} 5$ label in glutamate labelled by C2-pyruvate were measured as described by Heath \& Phillips (1972). 
Measurement of the ${ }^{14} \mathrm{C}$ isotope effect in the pyruvate carboxylase reaction

Pyruvate carboxylation with $\left[{ }^{14} \mathrm{C}\right]$ bicarbonate of measured S.R. (Rose, 1976) was coupled to the MDH reaction to give malate, the S.R. of which was measured. All volumetric apparatus was standardized by weighing.

Reactions were carried out in $80 \mathrm{~mm}$-Tris $/ \mathrm{HCl}$, pH8.0, containing 2mM-ATP, $9 \mathrm{~mm}-\mathrm{MgSO}_{4}$, $160 \mu \mathrm{M}$-acetyl-CoA and $25 \mathrm{~mm}$-bicarbonate with about $200 \mathrm{kBq}$ of $\left[{ }^{14} \mathrm{C}\right]$ bicarbonate. Since the kinetics depend on pyruvate concentration (McClure et al., 1971a; McClure \& Lardy, 1971), half the reactions were carried out with $0.2 \mathrm{mM}$ pyruvate and $0.3 \mathrm{~mm}-\mathrm{NADH}$ and half with $8 \mathrm{~mm}$ pyruvate and $0.16 \mathrm{~mm}-\mathrm{NADH}$. The total volume was $6 \mathrm{ml}$, in an $8 \mathrm{ml}$ firmly capped plastic vial. For measurement of total label and bicarbonate S.R., specimens $(0.2 \mathrm{ml}$, two for each) were taken with the same constriction pipette throughout. The reaction was then started by adding to each vial extra acetyl-CoA $(0.01 \mathrm{ml}$ of $60 \mathrm{~mm})$ and pyruvate carboxylase (1.7nkat, measured the same day). It was stopped by addition of $\mathrm{HClO}_{4}(0.8 \mathrm{ml}$ of $1.0 \mathrm{M})$ when about $80 \%$ of the pyruvate (at the low concn.) or $80 \%$ of the NADH (at the high) had been consumed, thus ensuring that the results would be independent of any isotope effect in the MDH reaction, since conversion of oxaloacetate into malate was substantially complete. $\mathrm{K}_{2} \mathrm{CO}_{3}$ was added in an amount insufficient to neutralize the acid, and the $\mathrm{CO}_{2}$ removed by concentration of the solution in a stream of $\mathrm{N}_{2}$ at $55^{\circ} \mathrm{C}$. The solution was then neutralized with $\mathrm{K}_{2} \mathrm{CO}_{3}$, and malate was separated and its S.R. measured in duplicate or triplicate as above. Chromatography showed that conversion into citrate was substantially complete: no label was recovered as malate, but $98.7 \pm 0.5 \%$ (6) was recovered as citrate.

\section{Kinetic experiments with PEPCK}

PEP formation was followed in $50 \mathrm{~mm}$ Tris/ $20 \mathrm{~mm}-\mathrm{KHCO}_{3}$ buffers (pH7.0 or 7.5 ) or $50 \mathrm{mM}-\mathrm{Tris} / \mathrm{HCl}$ (pH 8.0) by the rate of change of NADH absorbance at $334 \mathrm{~nm}$ in mixtures containing equimolar $\mathrm{NAD}^{+}$and malate, $1 \mu \mathrm{kat}$ of $\mathrm{MDH}$, and $1.5 \mathrm{mM}-\mathrm{Mg}^{2+}$ or $-\mathrm{Mn}^{2+}$ and other reagents as specified in the Results section. Initial [oxaloacetate] then equalled initial [NADH]. In accordance with theory the initial rate was $2 \mathrm{~d}[\mathrm{NADH}] / \mathrm{d} t$, the mean value of which stayed within $3 \%$ of its initial value until [NADH] had increased by more than $40 \%$. This method appears to be new for measurement of PEPCK. It gave a value for the maximal activity at $\mathrm{pH} 8.0$ by a Michaelis plot that agreed within $2 \%$ of that measured by PEP production from saturating [oxaloacetate] (Pogson \& Smith, 1975). Total PEP production calculated from the increase in [NADH] (Bergmeyer, 1974; eqn. 10, p. 117) agreed within $3 \%$ of that measured in the cuvette contents after acidification with $\mathrm{HClO}_{4}$.

Oxaloacetate $/ \mathrm{CO}_{2}$ exchange was measured in solutions $(3 \mathrm{ml})$ that were $20 \mathrm{mM}$ in $\mathrm{KHCO}_{3}$ and contained $100 \mathrm{kBq}$ of $\left[{ }^{14} \mathrm{C}\right]$ bicarbonate. Portions $(1 \mathrm{ml})$ were transferred to $2 \mathrm{M}-\mathrm{HCl}(0.5 \mathrm{ml})$ before the start of the reaction to provide a blank, and at a set time after. Published methods gave blanks too high and unreproducible for the measurement of the slower rates, and the following method was adopted that gave blanks of 0.5 c.p.s. reproducible to $3 \%$ (coefficient of deviation from the mean). $\mathrm{K}_{2} \mathrm{CO}_{3}(1 \mathrm{M} ; 0.2 \mathrm{ml})$ was added to each acidified specimen, which was then gassed with $\mathrm{CO}_{2}$ for $10 \mathrm{~min}$, left sealed overnight in a $\mathrm{CO}_{2}$ atmosphere, and re-gassed with air for $10 \mathrm{~min}$. Exchange in the presence of PEP formation was carried out with the NAD-malate-MDH system described above. (The MDH slowed ${ }^{14} \mathrm{CO}_{2}$ removal by the above method).

For reactions catalysed by low concentrations of $\mathrm{Fe}^{2+}$ (as ferrous ammonium sulphate) and $\mathrm{Mn}^{2+}$, near-equilibrium concentrations of reactants were used (PEP, GDP, GTP, $\mathrm{KHCO}_{3}$ and oxaloacetate), and, to minimize breakdown of oxaloacetate and oxidation of $\mathrm{Fe}^{2+}$, these and PEPCK were added in rapid succession in small volumes $(10,10$ and $20 \mu \mathrm{l}$ respectively within $10 \mathrm{~s})$ after removal of the blank.

\section{Results}

Rates measured in vitro are converted into rates per $100 \mathrm{~g}$ body wt. by using a liver weight of $3.5 \mathrm{~g} / 100 \mathrm{~g}$. Usually 'per $100 \mathrm{~g}$ body wt.' is omitted from rates.

\section{Labelling of metabolites in blood and liver by $\left[{ }^{14} \mathrm{C}\right]-$ bicarbonate}

S.R.s were required as fractions of the S.R. of blood bicarbonate. Bicarbonate S.R. was measured in arterial blood, whereas most of the blood supply is portal (75-90\%; Mendell \& Hollenberg, 1971; Sasaki \& Wagner, 1971; Bredfeldt et al., 1983). In trial experiments the arterial/portal S.R. ratio was measured at the end of the infusion. A blood specimen was taken from the portal vein via a needle filled with mercury to minimize $\mathrm{CO}_{2}$ exchange with the atmosphere, and an arterial sample immediately afterwards. The value of the ratio was $1.054 \pm 0.011$ (11). The S.R. of the total hepatic blood supply was therefore in the range $0.95-0.97$ of the measured arterial value. The value 0.96 was used. 
The theoretical treatment is much simplified if it is confined to the positions shown as labelled in Scheme 1. The contribution to total labelling of label in other positions can be calculated from the $\mathrm{Cl}$ and $\mathrm{C} 6$ labelling of glucose (assuming that $\mathrm{Cl}$ and $\mathrm{C} 2$ labelling were equal, and also $\mathrm{C} 6$ and $\mathrm{C5}$ labelling). Of total label in glucose, $1.51 \pm 0.16 \%$ (4) was in the $\mathrm{Cl}$ position and $1.09 \pm 0.08 \%$ (4) was in the $\mathrm{C} 6$ position, whence $5.6 \%$ of the label was not in the $\mathbf{C} 3,4$ positions, and $94.4 \%$ was. Since blood alanine, glycerol and lactate become labelled solely from glucose, the same fraction of their labelling was C1. Aspartate, citrate and malate were labelled by bicarbonate and lactate proportionately to the S.R.s of these compounds, giving 0.99 of their label in $\mathrm{C} 1,4$ [C6,1 in citrate, denoted by $\mathrm{C}(\mathrm{M} 1, \mathrm{M} 4)]$. In accordance, $97-100 \%$ of the citrate and malate label was found in these positions. The corrected S.R.s are shown in Table 1.

It should, however, be noted that the downward correction of the S.R. of glucose is not appropriate

Table 1. Concentrations and relative S.R.s of blood and liver metabolites during infusion of $\left[{ }^{14} \mathrm{C}\right]$ bicarbonate S.R.s are given relative to that of bicarbonate in the hepatic blood supply. The results of three experiments are summarized, each with four rats. In one experiment only blood metabolites were measured, in the other two blood glucose and bicarbonate and liver metabolites. Measurements on one specimen each of malate and citrate are omitted, as a wrong fraction was taken, so that the blanks could not be matched. The $\mathrm{C} 4 / \mathrm{Cl}$ ratio in aspartate was measured in a separate experiment. All S.R.s have been corrected to correspond to C3,4-labelling in glucose, and $\mathrm{C1}, 4-$ or $\mathrm{Cl}$-labelling in all other metabolites (see the text). Results are given as means \pm S.E.M. $(n)$.

Metabolite

Concn.

S.R.
Blood $(\mu \mathrm{mol} / \mathrm{ml})$

$\begin{array}{lll}\text { Glucose } & - & 0.870 \pm 0.016(12) \\ \text { Alanine } & 0.50 \pm 0.05(4) & 0.212 \pm 0.010(4) \\ \text { Glycerol } & 0.096 \pm 0.002(4) & 0.097 \pm 0.008(4) \\ \text { Lactate } & 0.69 \pm 0.07(4) & 0.251 \pm 0.013(4) \\ \text { iver }(\mu \mathrm{mol} / \mathrm{g}) & & \\ \text { Glucose } & - & 0.902 \pm 0.026(8) \\ \text { Alanine } & 0.29 \pm 0.03(8) & 0.195 \pm 0.017(4) \\ \text { Aspartate } & 0.75 \pm 0.08(8) & 0.739 \pm 0.055(8) \\ \text { C(M1)-Citrate } & 0.155 \pm 0.005(7) & 0.590 \pm 0.012(7) \\ \text { C(M4)-Citrate } & 0.394 \pm 0.007(7) \\ \text { Glutamate } & 2.68 \pm 0.16(8) & 0.411 \pm 0.007(8) \\ \text { Lactate } & 0.166 \pm 0.011(8) & 0.281 \pm 0.021(8) \\ \text { C1-Malate } & 0.222 \pm 0.005(7) & 0.394 \pm 0.012(7) \\ \text { C4-Malate } & 0.443 \pm 0.011(7)\end{array}$

S.R. ratios, $\mathrm{C} 4 / \mathrm{Cl}$

$\begin{array}{ll}\text { Aspartate } & 1.380 \pm 0.024(4) \\ \text { Citrate } & 0.658 \pm 0.013(7) \\ \text { Malate } & 1.121 \pm 0.010(7)\end{array}$

if labelling in positions other than $\mathrm{C} 3,4$ is attributable to the pentose phosphate cycle or other pathways above PEP on the gluconeogenic chain, since the S.R. of glucose was always calculated from that of C1-PEP. Redistribution of label between PEP and glucose does not affect the total S.R. of glucose regarded as a product of C1-PEP.

There was good agreement between the S.R.s in blood and liver of alanine, glucose and lactate. To test theory, however, only the values in blood were used, since labelling by blood lactate and alanine obviously gives better estimates of the effects of the Cori and alanine cycles, and the method for the measurement of the S.R. of glucose in blood has been more fully validated (Heath et al., 1977) than for that in liver.

The S.R.s of glutamate and C(M4)-citrate were equal, as expected if glutamate was labelled solely via citrate and the glutamate pool was not diluted measurably by proteolysis or exchange (perhaps via glutamine) with exogenous glutamate. The mean S.R. of glutamate and C(M4)-citrate was used in calculations.

\section{Ancillary measurements}

(1) The ${ }^{14} \mathrm{C}$ isotope effect in the pyruvate carboxylase reaction. Two sets of measurements were made, giving statistically homogeneous results with an over-all mean value of the bicarbonate/malate S.R. ratio of $0.992 \pm 0.008(10)$, independent of pyruvate concentration. The S.E.M. allowed for all known sources of absolute error, and should measure accuracy, not merely reproducibility.

There was therefore no need to correct results for an isotope effect. It was less than that of the malic enzyme reaction, ratio 0.94 (calculated from the ${ }^{13} \mathrm{C}$ effect given by Schimerlik et al., 1975), but similar to that of the isocitrate dehydrogenase reaction (O'Leary \& Limburg, 1977).

(2) $\mathrm{CO}_{2}$ fixation by PEPCK. Measurement of the maximal rate of PEP formation by PEPCK by the method of Pogson \& Smith (1975) gave the value $8.3 \pm 0.3 \mu \mathrm{mol} / \mathrm{min}$ per $\mathrm{g}$ of liver (6), i.e. $29 \mu \mathrm{mol} / \mathrm{min}$ per $100 \mathrm{~g}$ body wt. This rate is denoted by $V_{m}$. The rate of formation of PEP in our rats that was required to account for glucose production was $6.2 \mu \mathrm{mol} / \mathrm{min}$ per $100 \mathrm{~g}$ body wt., i.e. $0.21 V_{\mathrm{m}}$. Our aim was to measure the $\mathrm{CO}_{2}$-exchange rate when the net rate of PEP formation was about $0.21 V_{\mathrm{m}}$, with concentrations of reactants similar to those in the cytosol, i.e. in the ranges oxaloacetate 7-20 $\mu \mathrm{M}$ (Siess et al., 1976), PEP $200 \mu \mathrm{M}$ (calculated from results given by Hems \& Brosnan, 1970) and total guanosine nucleotides $0.5-1 \mathrm{mM}$, with [GTP]/[GDP] ratios of 2-4 (Clifford et al., 1972). Concentrations of $\mathrm{KHCO}_{3}$ and $\mathrm{Mg}^{2+}$ were $20 \mathrm{mM}$ and $1.5 \mathrm{mM}$ respectively. Rates were measured at pH7.0 and 7.5. Since $200 \mu \mathrm{M}$-PEP only inhibited

Vol. 227 
Table 2. PEP and oxaloacetate $(\mathrm{OA})$ production and $\mathrm{CO}_{2}$ incorporation by $\mathrm{PEPCK}$ at $37^{\circ} \mathrm{C}$ and $\mathrm{pH} 7.0$ See the Materials and methods section for experimental details. Results in lines 1-8 were obtained with the NAD ${ }^{+}$ malate-MDH system. This could not be used in the presence of $\mathrm{Fe}^{2+}$, results with which (lines 9-12) were measured with near-equilibrium concentrations of reactants in $50 \mathrm{~mm}$-Hepes buffer with $2 \mathrm{~min}$ reaction time, and rates were calculated by the equation:

$$
\text { Rate }=-[Q \cdot \ln (1-F)] / t
$$

where $Q=$ [oxaloacetate], $t=$ reaction time and $F=$ terminal value of the oxaloacetate/bicarbonate S.R. ratio. In these systems net oxaloacetate formation was also measured in the absence of initial oxaloacetate and GTP. To permit comparison with rates in vivo, all rates are shown as fractions of the value of $V_{m}$ for PEP formation measured on the same or the following day with the $\mathrm{NAD}^{+}-$malate-MDH system in the absence of transition metals. S.E.M. values are shown when $n=3$ or 4 .

Initial concn. $(\mu \mathrm{M})$

Flow rates $/ V_{\mathrm{m}}$

\begin{tabular}{|c|c|c|c|c|c|c|c|}
\hline Code & {$[\mathrm{OA}]$} & [PEP] & [GTP] & [GDP] & {$\left[\mathrm{Fe}^{2+}\right]$} & $\mathrm{CO}_{2}$ incorp. & Net flow \\
\hline & & & & & & & To PEP \\
\hline 1 & 19 & 0 & 1000 & 0 & 0 & $0.056 \pm 0.002$ & $0.40 \pm 0.02$ \\
\hline 2 & 10 & 0 & 670 & 0 & 0 & $0.049 \pm 0.001$ & $0.31 \pm 0.01$ \\
\hline 3 & 20 & 0 & 670 & 170 & 0 & $0.055^{-}$ & 0.32 \\
\hline 4 & 20 & 0 & 670 & 330 & 0 & 0.055 & 0.23 \\
\hline 5 & 10 & $\mathbf{0}$ & 670 & 170 & 0 & 0.033 & 0.20 \\
\hline 6 & 8 & 0 & 670 & 330 & 0 & 0.035 & 0.16 \\
\hline 7 & 10 & 400 & 330 & 330 & 0 & $0.031 \pm 0.001$ & $-0.01 \pm 0.01$ \\
\hline 8 & 22 & 400 & 330 & 330 & 0 & $0.037,0.040$ & $0.02,0.03$ \\
\hline & & & & & & & To oxaloacetate \\
\hline 9 & 9 & 400 & 330 & 330 & 0 & $0.11,0.13$ & $0.07,0.08$ \\
\hline 10 & 9 & 400 & 330 & 330 & 2 & $0.37,0.61$ & $0.29,0.33$ \\
\hline 11 & 18 & 800 & 330 & 330 & 0 & $0.18,0.20$ & - \\
\hline 12 & 18 & 800 & 330 & 330 & 2 & $0.41,0.45$ & - \\
\hline
\end{tabular}

PEP formation by $<20 \%$ when the [GTP]/[GDP] ratio was 2.0 or more, PEP was often omitted when PEP formation was measured.

Only the immediately relevant results are shown (Table 2). The required forward rate was achieved under realistic conditions with very low exchange rates $\left(<0.05 V_{m}\right)$. Even slower exchange rates were measured at $\mathrm{pH} 7.5$.

The exchange rate can be catalysed by $\mathrm{Fe}^{2+}$, although it is uncertain whether this takes place normally in vivo. Relevant findings are given by, among others, Bentle \& Lardy (1976, 1977), Colombo et al. (1978), Hammond \& Balinsky (1978), Jomain-Baum \& Schramm (1978), MacDonald \& Lardy (1978) and Reynolds (1980a,b,c). 3-Aminopicolinate stabilizes activation by $\mathrm{Fe}^{2+}$ and is a hyperglycaemic agent in vivo. If, as is generally considered to be the case, the first observation explains the second, an upper limit can be placed on the effective $\left[\mathrm{Fe}^{2+}\right]$ in vivo. The net rate of formation of PEP is maximally accelerated by about $2 \mu \mathrm{M}-\mathrm{Fe}^{2+}$, higher concentrations accelerating the back reaction (oxaloacetate formation) disproportionately. Hence hyperglycaemia requires $\left[\mathrm{Fe}^{2+}\right]$ stabilized by 3-aminopicolinate to be about $2 \mu \mathrm{M}$, and normal effective concentrations must be less.

We present results with $2 \mu \mathrm{M}-\mathrm{Fe}^{2+}$, since rates with lower concentrations were too low to be reproducible. This concentration raised the exchange rate by about $0.3 V_{\mathrm{m}}$ (the differences in values between lines 10 and 9 and 12 and 11 in Table 2). If GTP and oxaloacetate were omitted from the reaction mixture, the rate of oxaloacetate formation was found to be about $70 \%$ of the exchange rate. (Higher rates with $5 \mu \mathrm{M}-\mathrm{Fe}^{2+}$ and very low rates with $2 \mu \mathrm{M}-\mathrm{Mn}^{2+}$ were measured, but are not shown.) It appears likely therefore that in vivo, even if there is normally some activation by $\mathrm{Fe}^{2+}$, the rate of exchange would be substantially less than $0.3 V_{\mathrm{m}}, 8 \mu \mathrm{mol} / \mathrm{min}$ per $100 \mathrm{~g}$.

(3) The S.R.s of glutamate labelled by C1-and C2-pyruvate. The measured values were $10600 \pm 260(12)$ and $39600+1200$ c.p.m. $/ \mu \mathrm{mol}$ respectively. Of the latter $0.81 \pm 0.05 \%$ (6) of the label was in the $\mathrm{Cl}$ position and $5.4 \pm 0.3 \%$ (6) in the $\mathrm{C} 5$ position. Thus, corrected for recycling (see the Appendix), the C2,3-label was 35900 c.p.m./ $\mu \mathrm{mol}$, and its ratio to labelling by $\mathrm{C1}$ pyruvate was $3.38 \pm 0.15(24)$. This ratio is equivalent to $1+\mathrm{C} 3 / \mathrm{C} 2$, where $\mathrm{C} 3 / \mathrm{C} 2$ is the $\mathrm{C} 3 / \mathrm{C} 2$ S.R. ratio in glutamate measured $1.5 \mathrm{~min}$ after injection of C2-pyruvate, which is the usual measure of oxaloacetate-fumarate disequilibrium. Hence, to unify the treatment with that given by Heath \& Phillips (1972), the value $2.38 \pm 0.15$ will be re- 
ferred to as the $\mathrm{C} 3 / \mathrm{C} 2$ ratio in glutamate. It is very close to the values in other rats at $30^{\circ} \mathrm{C}$ ambient in other metabolic states.

\section{Discussion}

The relative S.R.s of bicarbonate, citrate, glucose and malate were very close to those given by Müllhofer et al. $(1977 a, b)$ in hepatocytes. If there was only one mitochondrial pool of oxaloacetate, and $\mathrm{CO}_{2}$ fixation was confined to the pyruvate carboxylase reaction, then calculation from the S.R.s of lactate and C4-citrate and the ratios $\mathrm{C} 4 / \mathrm{Cl}$ in malate and $\mathrm{C} 3 / \mathrm{C} 2$ in glutamate showed that the maximum possible S.R. of glucose in our experiments was $0.607 \pm 0.016$. This estimate was decreased to about 0.5 when allowance was made for gluconeogenesis from lightly labelled substrates such as glycerol. The lowest value that we measured was 0.79 .

It is theoretically possible to explain this discrepancy by postulating that about $45 \%$ of the total cellular citrate and glutamate were sequestered from labelling throughout the $2 \mathrm{~h}$ perfusion. It seems, however, highly unlikely that roughly equal, high, proportions of two compounds so dissimilar in structure, concentration and distribution between mitochondria and cytosol could be sequestered in this way except in cells that lacked the en- zymes for $\mathrm{CO}_{2}$ fixation, i.e. non-parenchymal cells. Sequestration in these cells, however, does not seem a plausible hypothesis either. It implies that the good agreement between results in vivo and in hepatocytes was merely a coincidence, and that citrate and glutamate concentrations in non-parenchymal cells, which constitute only about $10 \%$ of the liver mass, were several times higher than in parenchymal cells. There is indirect evidence that the last is not true of glutamate. According to Crisp $\&$ Pogson (1972) the main fuel of the citrate cycle in non-parenchymal cells is glucose; but there is little labelling of glutamate by $\left[\mathrm{U}-{ }^{14} \mathrm{C}\right]$ glucose in the starved rat (C. J. Threlfall, personal communication). Compartmental analysis of his results indicated that, if labelling was confined to cells that burned only glucose, these cells contained about $5 \%$ of the liver glutamate, not the $45 \%$ required. Models were therefore set up to test other hypotheses.

\section{Model for the basal rat}

The model (Scheme 2) represents the major pathways that interrelate the flow of carbon units in the citrate cycle and gluconeogenic chain. Three $\mathrm{CO}_{2}$-fixation reactions omitted by Mülhoffer $e$ al. $(1977 a, b)$ are included: PEPCK exchange (rate RCO); malate synthesis by malic enzyme (rate $\mathrm{RPM}$ ); and $\mathrm{CO}_{2}$ exchange by isocitrate dehydro-

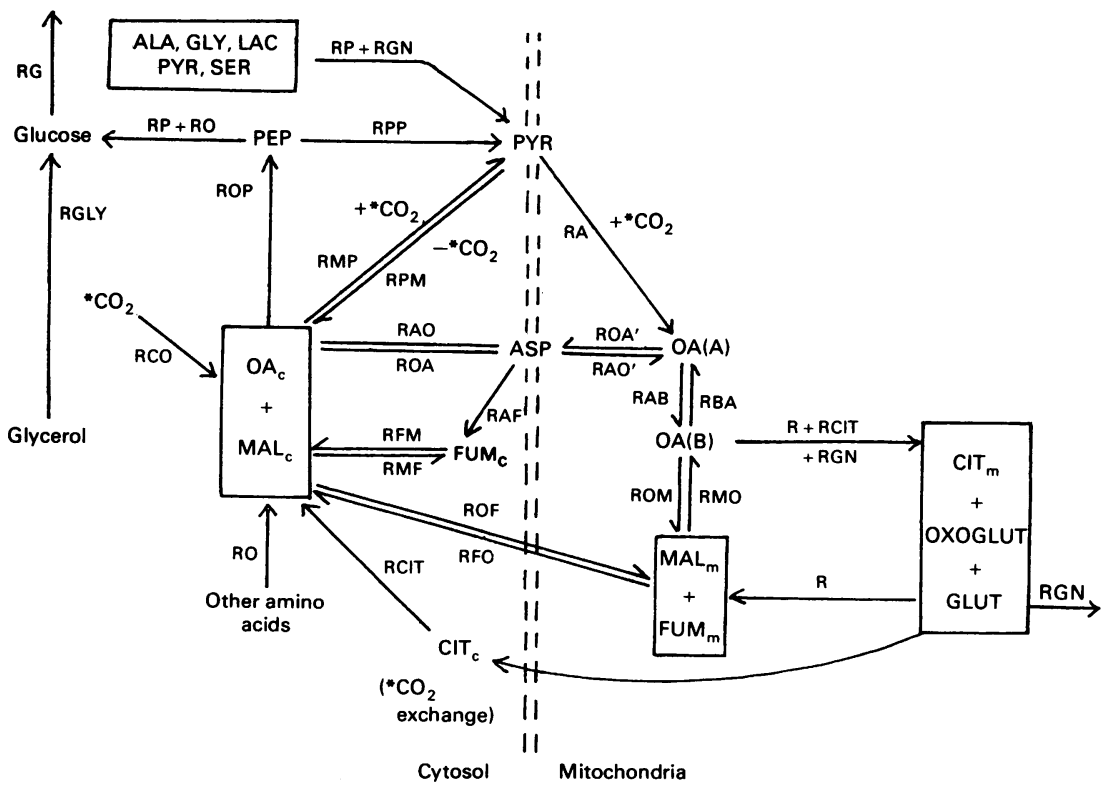

Scheme 2. Model 1 for the incorporation of label into hepatic metabolites from $\left[{ }^{14} \mathrm{C}\right]$ bicarbonate Abbreviations: ALA, alanine; ASP, aspartate; CIT, citrate; FUM, fumarate; GLUT, glutamate; GLY, glycine; LAC, lactate; MAL, malate; OA, oxaloacetate; OXOGLUT, 2-oxoglutarate; PYR, pyruvate; SER, serine; subscript 'c', cytosolic; subscript ' $\mathrm{m}$ ', mitochondrial. RGN denotes rate of loss of glutamine. RG, the replacement rate of glucose, is in $\mathrm{C}_{3}$ units. 
genase. The last was assumed to reach equilibrium in the cytosol (Sies et al., 1977), so that the C(M1) position of the citrate produced had an S.R. of unity. This citrate was assumed to be converted irreversibly (Plowman \& Cleland, 1967) into cytosolic oxaloacetate by citrate lyase at rate RCIT. [Since the experimental value of C(M1)-citrate was 0.59 (Table 1), mitochondrial citrate and bicarbonate were not in equilibrium.] Channelling of oxaloacetate was allowed for by introducing two mitochondrial oxaloacetate pools, $A$ and $B$, with exchange rate $\mathrm{RBA}$.

Heath \& Phillips (1972) showed that in the hepatic mitochondria of the post-absorptive rat malate and fumarate were near equilibrium, whereas malate and oxaloacetate were not. Similar methods show that the same is true in other metabolic states, including the basal state under study, but that in the cytosol malate and oxaloacetate are in equilibrium, whereas malate and fumarate are not (D. F. Heath, C. J. Phillips \& J. G. Rose, unpublished work). Consequently mitochondrial malate and fumarate can be represented by a single pool, as also can cytosolic malate and oxaloacetate. The exchange rates, RMO and RMF, between the compounds not in equilibrium had to be calculated from the data.

Only net loss of glutamine is shown (rate RGN), in accordance with other measurements (Aikawa et al., 1973). Exchange with blood is omitted, since this would have decreased the S.R. of glutamate below that of C(M4)-citrate.

Some known pathways are omitted or represented indirectly. Thus the pyruvate dehydrogenase reaction and pentose phosphate pathway are omitted, the former because it cannot incorporate label from bicarbonate or C1-pyruvate, the latter because it had little effect on glucose label- ling in our rats (nearly all the label was C3,4). Transport of material across the mitochondrial membrane to balance the ornithine cycle, to permit conversion of cytosolic aspartate into oxaloacetate and to provide reducing equivalents for gluconeogenesis are all represented by malate exchange (rate ROF) with a net flux (RFO-ROF) superposed, since these are the only processes involved that affect labelling.

The representation of aspartate by a single pool that exchanges only with Pool $\mathrm{A}$ and cytosolic oxaloacetate was used routinely for simplicity. The more complex modelling of this part of the system shown in Scheme 3 was used in some trial calculations, but was shown to give similar results in most respects to the simpler model, with $\mathrm{ROB}^{\prime}$ and RBO' taking on values close to those of $R A B$ and RBA in Scheme 2.

\section{Pre-assignment of parameter values}

Some rates in the liver could be calculated from published data.

(1) The $\mathrm{O}_{2}$ consumption of the liver under ketamine anaesthesia was $3.6 \pm 0.36 \mu \mathrm{mol} / \mathrm{min}$ per $\mathrm{g}$

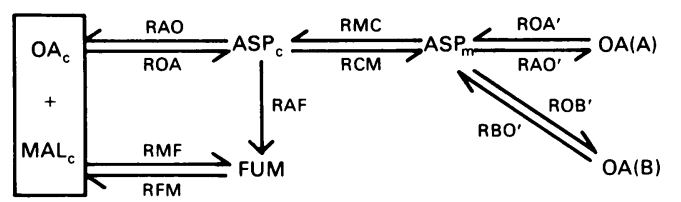

Scheme 3. Alternative model (Model 2) for the oxaloacetate-aspartate system

The two oxaloacetate pools, A and B, exchange via mitochondrial aspartate, which exchanges with cytosolic aspartate, and this in turn with cytosolic oxaloacetate. Other pathways are as in Scheme 2.

Table 3. Pre-set values of parameters

The evidence for the ranges shown is given in the text. Rates are in $\mu \mathrm{mol} / \mathrm{min}$ per $100 \mathrm{~g}$. Abbreviation and symbols: other AAs, other amino acids; otherwise as in Scheme 2 and its legend.

$\begin{array}{lc}\text { RG (C } 3 \text { units to glucose) } & 6.8 \\ \text { RGLY (glycerol to glucose) } & 0.64 \\ \text { RP (ALA + GLY + LAC+ PYR + SER to glucose) } & 5.6 \\ \text { RO (other AAs to glucose) } & 0.56 \\ \text { RAF (urea production) } & 1.4-1.9 \\ \text { RFO-ROF (net malate transport to cytosol) } & -0.5-0.5 \\ \text { R (citrate cycle flux) } & 4.0 \pm 0.4 \\ \text { RMF (cytosolic MAL-FUM exchange) } & 10-30 \\ \text { RCIT (CIT to OA by citrate lyase) } & 0.0-1.0 \\ \text { RPM (PYR to MAL by malic enzyme) } & 0 \\ \text { RMP+RPP (futile cycling by malic enzyme + pyruvate kinase) } & 0.0-1.4 \\ \text { RCO (CO fixation by PEPCK) } & 2-4 \\ \text { Fe'-activated } & 0.5-2 \\ \text { Not activated } & 0.25-0.75 \\ \text { RGN (net loss of glutamate as glutamine) } & 0.0-0.24 \\ \text { S.R.s of 'other' AAS } & \end{array}$


liver wt. (Bredfeldt et al., 1983), of which at least $90 \%$ should be accounted for by oxidation of fat to acetyl-CoA and of acetyl-CoA in the citrate cycle (see, e.g., Williamson et al., 1969). The C5 labelling of glutamate by $\mathrm{C} 2$-pyruvate showed that less than $3 \%$ of the acetyl-CoA used by the cycle came from pyruvate, and hence more than $97 \%$ came from fat. The oxidation rate was then equivalent to $8.0 \pm 0.8 \mu$ unit of $\mathrm{CH}_{2} / \mathrm{min}$ per $100 \mathrm{~g}$ body wt., and $R$, the rate of conversion of 2-oxoglutarate into malate in the cycle, can be shown to have been 4.0-RCIT $/ 3-\mathrm{RGN} / 2 \mu \mathrm{mol} / \mathrm{min}$. This rate is a little less than that calculated in a kinetic isotope study in vivo (Sauer et al., 1970), but, since it is at least twice as much as most values measured in vitro, a lower value was sometimes used.

(2) The relative rates of uptake of gluconeogenic precursors by the liver were taken from measurements made on rats under anaesthesia by Aikawa et al. (1973) and Bloxam (1972). Assuming that pyruvate uptake was $10 \%$ of lactate uptake, the relative rates were: pyruvate + lactate, $68 \%$; alanine, $17 \%$; serine + glycine, $6 \%$ (all via pyruvate); others, $9 \%$. Those amino acids entering the system via pyruvate were all assumed to have the same S.R. as lactate + alanine, the others to have S.R.s up to this value. Other amino acids entered in a number of ways, e.g. via glutamate, aspartate and fumarate, but all are shown as directly entering the cytosolic oxaloacetate pool, since their main effect was to dilute the label in it. Aikawa et al. (1973) also give the net loss of glutamine as about half the alanine uptake, and this was assumed to be the case.

(3) ATP citrate lyase activity in the liver of the starved rat is $1-5 \mu \mathrm{mol} / \mathrm{min}$ (Srere \& Foster, 1967). The mitochondrial/cytosolic [citrate] ratio is about 20 (Tischler et al., 1977), whence cytosolic [citrate] is about one-third of the $K_{\mathrm{m}}$ value (Inoue et ál., 1966). These results give $0.5 \mu \mathrm{mol} / \mathrm{min}$ as the most likely value of SCIT, with a range $0-1.0$.

(4) 'Futile' cycling of pyruvate transfers label from the $\mathrm{C} 2$ to the $\mathrm{C} 3$ position, and causes liver glutamate to be labelled in the $\mathrm{C} 4$ as well as the $\mathrm{C5}$ position. The $\mathrm{C} 4 / \mathrm{C} 5$ ratio in glutamate is very low $(<0.05)$ in post-absorptive rats (Heath \& Phillips, 1972), corresponding to low rates of 'futile' cycling. Friedmann et al. (1971) showed that 'futile' cycling was lower in the starved rat, and also pointed out that carbon labelling cannot distinguish between recycling via malic enzyme (RMP) and pyruvate kinase (RPP). Over-all, these results indicate that the rate of 'futile' cycling (RMO+RPP) was unlikely to exceed $20 \%$ of the gluconeogenic flux, and was probably much less.

(5) The rate RPM was taken to be zero, since malic enzyme concentration is low in the liver of the starved rat (Veech et al., 1969) and its $K_{\mathrm{m}}$ for pyruvate is about 100 times cytosolic [pyruvate]
(Hsu et al., 1967; measured on the pigeon liver enzyme).

Two whole-body rates are known. That of glucose replacement, measured in $\mathrm{C}_{3}$ units under similar conditions, is $6.8 \pm 0.2 \mu \mathrm{mol} / \mathrm{min}$ (Heath et al., 1977). The rate of conversion of glycerol into glucose, $0.64 \mu \mathrm{mol} / \mathrm{min}$, was calculated from the whole-body $\mathrm{O}_{2}$ consumption (Stoner \& Marshall, 1971), corrected for the effects of anaesthesia (Denckla, 1970) and the respiratory quotient, 0.75 (Freminet et al., 1975), assuming release of $1 \mathrm{~mol}$ of glycerol per 48 fat carbon atoms oxidized and $80 \%$ conversion of glycerol into glucose (D. F. Heath, unpublished work).

To calculate hepatic glucose output from that in the whole body renal output must be estimated. Two types of experiment have led to irreconcilable values. Dzurik et al. (1963) and Churchill et al. (1973) measured the dependence of renal uptake and output on the concentrations of circulating glucose, which in our rats were close to or above those at which there was net renal output. According to those authors, renal gluconeogenesis could be ignored. Kida et al. (1978), however, calculated rapid outputs from the rates of fall of glucose concentration and S.R. in rats that had been functionally eviscerated by ligation of the inferior and superior mesenteric and coeliac arteries. In starved rats renal output was $46 \%$ of the whole-body utilization rate. The contribution is likely to be much less in the intact rat, since the decrease in glucose concentration during the experiment would permit faster renal output, the removal of the liver would increase the supply of gluconeogenic precursors, and evisceration would decrease the glucose utilization rate (by over onie-half, according to Achou \& Hetenyi, 1974); with respect to which the percentage was calculated. Moreover, renal activities of PEPCK and pyruvate carboxylase are only 20 $25 \%$ of the hepatic values in the starved rat (Scrutton \& Utter, 1968). We do not think that renal output can be more than $30 \%$ of the total, and have taken this as the maximum.

The kidneys should produce glucose of lower S.R. than does the liver, because glutamine replaces alanine as precursor (see, e.g., Snell, 1980). Synthesis from glutamine by-passes the pyruvate carboxylase reaction, and glutamine itself can be only lightly labelled, so that the S.R. of glucose from glutamine must be low. With glutamine substituted for alanine, Model 1 (Scheme 2) gives values for the S.R. of renal glucose output in the range $0.5-0.6$; and the value 0.6 was used to calculate the S.R. of the hepatic output from the experimental S.R. of the combined outputs. This procedure gives a minimum S.R. of hepatic output for any assumed renal contribution to total gluconeogenesis, since Wang \& Kurokawa (1984) have 
shown that all cortical cells use glutamine readily for gluconeogenesis and that in some it is a better precursor of glucose than is pyruvate. It is therefore likely that more of the renal glucose output came from glutamine than we have assumed, with consequent over-estimation of the S.R. of the renal glucose output and under-estimation of the S.R. of the hepatic output. Any such error is in the right direction, since it strengthens the test of the hypotheses put forward below.

Urea output, equal to RAF, the rate of conversion of asparate into fumurate in the ornithine cycle, was put at $1.4-1.9 \mu \mathrm{mol} / \mathrm{min}$. The mean daily rate is about $1.1 \mu \mathrm{mol} / \mathrm{min}$ (Schimke, 1962) and is increased by starvation, when in the conscious rat a rate of $2.8 \mu \mathrm{mol} / \mathrm{min}$ has been measured (Cunningham, 1975). The value taken is not critical.

Reducing equivalents must leave the mitochondria to balance uptake of those gluconeogenic precursors that enter the mitochondria as pyruvate. This rate of uptake was $1.6 \mu \mathrm{mol} / \mathrm{min}$ in the absence of renal gluconeogenesis, and therefore roughly balanced the mitochondrial uptake of malate equivalent to the fumarate produced in the ornithine cycle. Over-all, there may have been either a net gain or loss, but it was unlikely to have exceeded $0.5 \mu \mathrm{mol} / \mathrm{min}$.

The rate of exchange of malate across the mitochondrial membrane must at least equal the net rate of production of cytosolic oxaloacetate by deamination of aspartate in order to balance the mandatory transport of 2-oxoglutarate and phosphate (Bücher \& Sies, 1980), i.e. it must be 3$4 \mu \mathrm{mol} / \mathrm{min}$ if renal glucose output is zero and $1.5-$ $2 \mu \mathrm{mol} / \mathrm{min}$ if renal glucose output is $30 \%$ of the total glucose-replacement rate. Since the activities of the transporters could support rates 5-10 times faster at the prevailing malate concentrations (Palmieri et al., 1971), the actual rates may exceed those required for gluconeogenesis. There is no obvious biochemical reason, however, why exchange across the mitochondrial membrane has to involve complete mixing of the malate used for transport with either the cytosolic pool involved in gluconeogenesis or the mitochondrial pool in the citrate cycle, and malate for transport may be channelled. Hence ROF, which measures exchange between the gluconeogenic and citrate-cycle pools, may be less than the transport rate, although not zero, since malate can be used to transport reducing equivalents in either direction across the mitochondrial membrane.

\section{Computations}

Specific carbon labelling was related to the S.R.s of bicarbonate (arbitrarily set at unity) and lactate by 11 equations linear in the parameters in Model 1 (Scheme 2) and 13 in Model 2 (Scheme 3), from solutions of which calculated data values were obtained. There were six usable data values: the S.R.s of glucose; C4-malate and C(M4)-citrate: the $\mathrm{C} 4 / \mathrm{Cl}$ ratios in malate and aspartate; and the $\mathrm{C} 3 / \mathrm{C} 2$ ratio in glutamate. [The $\mathrm{C}(\mathrm{M} 4) / \mathrm{C}(\mathrm{M} 1)$ ratio in citrate was not related to any parameters that were included in the Models, and the S.R. of aspartate could not be accounted for; see below.] The values of six parameters could therefore be calculated provided that the values of the rest were preset. Calculation, by a PDP 11/34 mini-computer, used a standard iterative linearization method continued until an iteration altered no parameter value by more than $0.1 \%$.

The parameters calculated were ROM, RMF, RAO, RCO $\left(\mathrm{CO}_{2}\right.$ fixation by PEPCK) and MALR (mitochondrial/cytosolic [malate] ratio), and either RBA (inverse measure of channelling) or $\mathbf{R}$ (citrate-cycle flux). When $\mathbf{R}$ was calculated, RBA was set at $500 \mu \mathrm{mol} / \mathrm{min}$, corresponding to negligible channelling. Failure to obtain an acceptable value of $R$ then provided evidence for channelling.

Over 300 combinations of pre-set parameter values, that covered the extremes of acceptable ranges (Table 3), were used. Finally, for each of 12 of these combinations the effects of data variances, including those of citrate-cycle flux and lactate S.R., were found by varying all data values simultaneously by using a randomly generated table of normal deviates to get 60-100 data sets, from each of which parameter values were calculated.

The main conclusion was that there was no set of parameters and data values that was consistent with zero $\mathrm{CO}_{2}$ fixation by PEPCK or zero channelling of oxaloacetate. Whenever zero channelling was assumed, the calculated value of the citratecycle flux was at least 2.5 S.E.M. high, and usually the calculated rate of $\mathrm{CO}_{2}$ exchange on PEPCK exceeded $6 \mu \mathrm{mol} / \mathrm{min}$.

There were two anomalies. First, the calculated S.R. of aspartate was always too high by about $25 \%$. Failure of aspartate to reach isotopic equilibrium with its precursors has been reported in mitochondria by Duszynski et al. (1978) and found by one of us (D. F. Heath, unpublished work) in the liver in vivo after $\mathrm{Cl}$-octanoate injection. It seems that some cellular aspartate is sequestered from the pathways labelled. Secondly, the calculated rates of conversion of cytosolic oxaloacetate into aspartate (ROA) were only $10-30 \mu \mathrm{mol} / \mathrm{min}$, lower than expected from the transaminase activity in the cytosol. Since the calculated values were highly dependent on the model used for aspartate, Model 2 (Scheme 3), giving values twice as high, they are not listed or discussed further.

Some parameter values could be varied over the whole of their likely ranges, with little effect on cal- 
culated values. This was the case with the rates of urea synthesis (RAF), futile cycling (RMP + RPP), net malate transport (ROF - RFO) and the citrate lyase reaction (RCIT) and the S.R. of 'other' amino acids. Some of these were usually set to zero in calculations, since their values could not affect the analysis. The conversion of aspartate into oxaloacetate in mitochondria $\left(\mathrm{RAO}^{\prime}\right)$ is probably slow (Duszynski et al., 1978), and this also was usually made zero, but it was checked that rates as high as $200 \mu \mathrm{mol} / \mathrm{min}$ only raised RBA by a factor of 1.5 .

Table 4 illustrates some of the findings. It is easier to picture them bearing in mind that, when RBA is $5 \mu \mathrm{mol} / \mathrm{min}$, about half of the oxaloacetate from pyruvate carboxylase is channelled to the cytosol without mixing with that in the citrate cycle.

Variance in the data caused substantial variance in parameter values, which were log-normally rather than normally distributed. Detailed discussion of small differences is not therefore warranted. Two conspicuous features, however, were the inverse relationships of ROF and RBA and the direct relationship between ROF and MALR. These were such that values of ROF above about $8 \mu \mathrm{mol} / \mathrm{min}$ were incompatible with real (positive) values of RBA and/or finite values of MALR. This may imply some channelling of malate transport, since this maximum rate is well below the capacity of the transporters (see above). In Table 4 the first value of ROF in each group with the same renal contribution corresponds to heavy channelling, and the second to the rate that balances 2-oxoglutarate transport. The calculated channelling of oxaloacetate was about twice as great with the second as with the first. Our results are incompatible with the very rapid exchange of malate across the mitochondrial membrane, for which there is evidence in kidney cortex slices (Rognstad, 1970; Rognstad \& Katz, 1973).

The calculated rate of $\mathrm{CO}_{2}$ fixation by PEPCK (RCO) was very dependent on the choice of values of other parameters; but most values lay in the range $1-4 \mu \mathrm{mol} / \mathrm{min}$. Such rates probably imply slight activation of PEPCK by $\mathrm{Fe}^{2+}$ ions (see ' $\mathrm{CO}_{2}$ fixation by PEPCK' above).

The apparent trend towards lower channelling of oxaloacetate with greater renal contribution to glucose output may be misleading, since somewhat lower (and plausible) estimates of the S.R. of renal glucose output (see under 'Pre-assignment of parameter values' above) eliminated it.

In the above it was assumed that hepatic glutamine output in our rats was similar to that in those studied in rats after major surgery by Aikawa et al. (1973). If, instead, there was assumed to be no loss of glutamine, estimates of oxaloacetate channelling were little affected, but those of malate channelling and MALR (the mitochondrial/cytosolic [malate] ratio) were increased, the latter to values 2-4 times higher than the highest measured in vitro (about 4: Tischler et al., 1977; Bücher \& Sies, 1980), unless malate channelling was almost complete (ROF near 0 ).

Two data values may have contained systematic errors. First, the citrate-cycle flux, R, may have been overestimated (see 'Pre-assignment of parameter values' above). Lowering the flux (see the third column for $15 \%$ renal output in Table 4) decreased RBA considerably, i.e. increased the estimate of oxaloacetate channelling. Secondly, the glucose S.R. may have been over-corrected downwards for labelling in the $\mathrm{C} 1,2,5,6$ positions (see the Results section). The use of the uncorrected

Table 4. Examples of sets of calculated parameter values consistent with Scheme 2

Rates are in $\mu \mathrm{mol} / \mathrm{min}$ per $100 \mathrm{~g}$ body wt. For definitions of parameters see Scheme 2 and Table 3 . Throughout, the following were set at zero: $\mathrm{RAO}^{\prime}$, RMP + RPP, net malate flux, and the S.R. of 'other' amino acids; and SCIT = 0.5 and $\mathrm{LAF}=1.9$. The rate of glutamine output was put equal to half the alanine uptake (Aikawa et al., 1973).

Renal glucose output (\% of total) ... 0

15

$\begin{array}{lrr}\text { Pre-set values } & & \\ \text { ROF (malate exchange) } & 0.5 & 3.3 \\ \text { R (citrate-cycle flux) } & 4.0 & 4.0 \\ \text { RGN (glutamine output) } & 0.5 & 0.5 \\ \text { RG (hepatic glucose output) } & 6.8 & 6.8 \\ \text { Calculated } & & \\ \text { RBA (channelling) } & 5.0 & 2.8 \\ \text { RMF (fumarase cytosolic) } & 32.2 & 34.1 \\ \text { RMO (MDH mitochondrial) } & 11.0 & 11.5 \\ \text { RCO (PEPCK exchange) } & 0.7 & 1.4 \\ \text { MALR ([malate] ratio) } & 2.3 & 4.2\end{array}$

* For this one set S.D. ranges are shown, assuming log-normal distributions, to show the effects of data variance (see the text). 
value also decreased RBA. It is also likely that glycerol production exceeded that assumed, since lipolysis in early starvation usually exceeds the rate of oxidation of fat. If so, then RP (Scheme 2) was overestimated. Again, lessening its value increased the estimate of channelling.

Effects of two types of liver-cell heterogeneity, between parenchymal and non-parenchymal, and within the parenchyma, were investigated by simulation.

If, as discussed above, non-parenchymal cells contained about $5 \%$ of the liver metabolites and these were unlabelled, the S.R.s measured were about $5 \%$ lower than the true values in parenchymal cells. Raising the S.R.s of citrate, glutamate and malate by $5 \%$ had only small effects on any parameter value.

The slight C5-labelling of glutamate showed that few cells were glycolytic, and these may have been non-parenchymal. In the parenchymal cells, however, the glucose output per cell presumably showed variance like any other biochemical property. The higher the gluconeogenic rate, the higher the S.R. of the glucose produced and the more channelling was required. Thus there had to be more than average channelling in cells with more than average rates of gluconeogenesis. The evidence that there was channelling in some cells is therefore stronger than appears from the analysis of mean data values.

Our results seem to rule out the channelling of the bicarbonate released from the citrate cycle towards pyruvate carboxylation that was suggested to occur by Mehlman \& Walter (1968). The calculated S.R. of the $\mathrm{CO}_{2}$ from the citrate cycle was about $\mathbf{0 . 3}$, so that channelling would have lowered the S.R. of the precursor bicarbonate and raised the relative S.R.s of all its metabolites. A rise of a few per cent would merely have increased the estimate of oxaloacetate channelling, but a rise of $30 \%$ would have made our results inexplicable. Apparently blood and cellular bicarbonate were almost in isotopic equilibrium in our experiments.

In summary, there is strong evidence that oxaloacetate produced by pyruvate carboxylase is channelled towards gluconeogenesis. Nearly every assumption made in the computations tended to lessen the estimate of channelling, i.e. to increase RBA, but it was never possible to account for the data without channelling. There may also have been channelling of the malate used for antiport on the mitochondrial membrane. Models that incorporate these features can correlate our data and those obtained from hepatocytes by Müllhofer $e t$ al. $(1977 a, b)$, by using rates of $\mathrm{CO}_{2}$ fixation by PEPCK that are in accord with those measured in vitro. Provided that there was some glutamine output from the livers of our rats, as expected from published studies, calculated values of the mitochondrial/cytosolic [malate] ratio were also similar to published values measured in vitro. Two rates were calculated more precisely than the rest, the rate of conversion of mitochondrial malate into oxaloacetate (RMO) and of cytosolic malate into fumarate (RMF), both of which can, potentially, be compared with independent estimates.

\section{Channelling and compartmentation}

The channelling of oxaloacetate towards gluconeogenesis does not imply 'compartmentation' in any physical sense, merely that the active sites for transamination are closer to the points of release of oxaloacetate from pyruvate carboxylase than to the active sites of citrate synthase. As has been pointed out in a review (Clegg, 1984), much channelling is to be expected in the highly structured milieu of the cell, and there is evidence for it in the MDHcitrate synthase part of the citrate cycle (Srere \& Henslee, 1980).

One effect of the channelling of oxaloacetate towards gluconeogenesis is to decrease the kinetic differences between those species in which PEPCK is all or nearly all cytosolic, such as the rat, and those in which it is partly or wholly mitochondrial, such as guinea pig, man and rabbit (Garber \& Hanson, 1971), since oxaloacetate from pyruvate can then be fed directly into the gluconeogenic chain whatever the distribution of PEPCK.

We thank Mr. Keith Wilford for his help in separating pyruvate carboxylase and PEPCK.

\section{References}

Achou, C. J. \& Hetenyi, G., Jr. (1974) Can. J. Physiol. Pharmacol. 52, 158-165

Agrelo, C. \& Dawson, W. (1968) J. Pharm. Pharmacol. 20, 959-960

Aikawa, T., Matsutaka, H., Yamamoto, H., Okuda, T., Ishikawa, E., Kawano, T. \& Matsumura, E. (1973) J. Biochem. (Tokyo) 74, 1003-1017

Ballard, F. J. \& Hanson, R. W. (1969) J. Biol. Chem. 244, 5625-5630

Bentle, L. A. \& Lardy, H. A. (1976) J. Biol. Chem. 251, 2916-2921

Bentle, L. A. \& Lardy, H. A. (1977) J. Biol. Chem. 252, 1431-1440

Bergmeyer, H. U. (ed.) (1974) Methods of Enzymatic Analysis, Academic Press, New York

Bergmeyer, H. U. (1975) Z. Klin. Chem. Klin. Biochem. 13, 507-508

Bloom, B. (1962) Anal. Biochem. 3, 85-87

Bloxam, D. L. (1972) Br. J. Nutr. 27, 233-247

Bredfeldt, J. E., Riley, E. M. \& Groszmann, R. J. (1983) Experientia 39, 729-730

Bücher, Th. \& Sies, H. (1980) in Cell Compartmentation and Metabolic Channelling (Nover, L., Lynen, F. \& Mothes, K., eds.), pp. 279-302, Gustav Fischer Verlag, Jena, and Elsevier, Amsterdam 
Churchill, P. C., Belloni, F. L. \& Churchill, M. C. (1973) Am. J. Physiol. 225, 528-531

Clegg, J. S. (1984) Am. J. Physiol. 246, R133-R151

Clifford, A. J., Riumallo, J. A., Baliga, B. S., Munro, H. N. \& Brown, P. R. (1972) Biochim. Biophys. Acta 277, 443-458

Colombo, G., Carlson, G. M. \& Lardy, H. A. (1978) Biochemistry 17, 5321-5329

Crisp, D. M. \& Pogson, C. I. (1972) Biochem. J. 126, 1009-1023

Cunningham, V. J. (1975) Br. J. Ind. Med. 32, 140-146

Denckla, W. D. (1970) J. Appl. Physiol. 29, 263-274

Duszynski, J., Mueller, G. \& LaNoue, K. (1978) J. Biol. Chem. 253, 6149-6157

Dzurik, R., Krajči-Lazáry, B. \& Niederland, T. R. (1963) J. Physiol. (London) 168, 782-786

Frayn, K. N. (1976) Diabetologia 12, 53-60

Freminet, A., Leclerc, L., Gentil, M. \& Poyart, C. (1975) FEBS Lett. 60, 431-434

Friedmann, B., Goodman, E. H., Jr., Saunders, H. L., Kostos, V. \& Weinhouse, S. (1971) Arch. Biochem. Biophys. 143, 566-578

Garber, A. J. \& Hanson, R. W. (1971) J. Biol. Chem. 246, 5555-5562

Goldstein, D. E. \& Curnow, R. T. (1973) Metab. Clin. Exp. 27, 315-323

Hammond, K. D. \& Balinsky, D. (1978) Int. J. Biochem. 9, 199-211

Heath, D. F. (1981) Adv. Physiol. Sci., Proc. Int. Congr. 28th 26, 63-70

Heath, D. F. \& Phillips, J. C. (1972) Biochem. J. 127, 453-470

Heath, D. F. \& Rose, J. G. (1976) J. Pharm. Pharmacol. 28, 151-153

Heath, D. F., George, D. R. \& Rose, J. G. (1971) Biochem. J. 125, 765-771

Heath, D. F., Frayn, K. N. \& Rose, J. G. (1977) Biochem. J. 162, 643-651

Hems, D. A. \& Brosnan, J. T. (1970) Biochem. J. 120, 105-111

Higgins, G. M., Berkson, J. \& Flock, E. (1932) Am. J. Physiol. 102, 673-682

Hsu, R. Y., Lardy, H. A. \& Cleland, W. W. (1967) J. Biol. Chem. 242, 5315-5322

Inoue, H., Suzuki, F., Fukunishi, K., Adachi, K. \& Takeda, Y. (1966) J. Biochem. (Tokyo) 60, 543-553

Jomain-Baum, M. \& Schramm, V. L. (1979) J. Biol. Chem. 253, 3648-3659

Jungermann, K. \& Sasse, D. (1978) Trends Biochem. Sci. $3,198-202$

Kida, K., Nakajo, S., Kamiya, F., Toyama, Y., Nishio, T. \& Nakagawa, H. (1978) J. Clin. Invest. 62, 721-726

Lange, K., Keller, K. \& Kolbe, H. (1972) NaunynSchmiedeberg's Arch. Pharmacol. 272, 454-457

MacDonald, M. J. \& Lardy, H. A. (1978) J. Biol. Chem. 253, 2300-2307

McClure, W. R. \& Lardy, H. A. (1971) J. Biol. Chem. 246, 3591-3596

McClure, W. R., Lardy, H. A. \& Kniefel, H. P. (1971a) J. Biol. Chem. 246, 3569-3578

McClure, W. R., Lardy, H. A., Wagner, M. \& Cleland, W. W. (1971b) J. Biol. Chem. 246, 3579-3583

Mehlman, M. A. \& Walter, P. (1968) Arch. Biochem. Biophys. 127, 590-600
Mendell, P. L. \& Hollenberg, N. K. (1971) Am. J. Physiol. 221, 1617-1620

Müllhofer, G., Schwab, A., Muller, C., von Stetten, C. \& Gruber, E. (1977a) Eur. J. Biochem. 75, 319-330

Müllhofer, G., Muller, C., von Stetten, C. \& Gruber, E. (1977b) Eur. J. Biochem. 75, 331-341

Ochoa, S., Salles, J. B. V. \& Ortiz, P. J. (1950) J. Biol. Chem. 187, 863-874

O'Leary, M. H. \& Limburg, J. A. (1977) Biochemistry 16, 1129-1135

Palmieri, F., Prezioso, G., Quagliariello, E. \& Klingenberg, M. (1971) Eur. J. Biochem. 22, 66-74

Philippidis, H., Hanson, R. W., Reshef, L., Hopgood, M. F. \& Ballard, F. J. (1972) Biochem. J. 126, $1127-$ 1134

Plowman, K. M. \& Cleland, W. W. (1967) J. Biol. Chem. 242, 4329-4247

Pogson, C. I. \& Smith, S. A. (1975) Biochem. J. 152, 401408

Reynolds, C. H. (1980a) Biochem. J. 185, 451-454

Reynolds, C. H. (1980b) Biochem. Pharmacol. 29, 325329

Reynolds, C. H. (1980c) Comp. Biochem. Physiol. B 65, 481-487

Rognstad, R. (1970) Biochem. J. 116, 493-502

Rognstad, R. \& Katz, J. (1973) Biochem. J. 132, 349-352

Rose, J. G. (1976) Anal. Biochem. 76, 358-360

Rose, J. G. (1981) Biochem.' Med. 26, 41-46

Sasaki, Y. \& Wagner, H. N. (1971) J. Appl. Physiol. 30, 879-884

Sasse, D., Katz, N. \& Jungermann, K. (1975) FEBS Lett. 57, 83-88

Sauer, F., Erfle, J. D. \& Binns, M. R. (1970) Eur. J. Biochem. 17, 350-363

Schimerlik, M. I., Rife, J. E. \& Cleland, W. W. (1975) Biochemistry 14, 5347-5354

Schimke, R. T. (1962) J. Biol. Chem. 237, 459-468

Scrutton, M. C. \& Utter, M. F. (1968) Annu. Rev. Biochem. 37, 249-302

Sies, H., Akerboom, T. P. M. \& Tager, J. M. (1977) Eur. J. Biochem. 72, 301-307

Siess, E. A., Brocks, D. G. \& Wieland, O. H. (1976) FEBS Lett. 69, 265-271

Snell, K. (1980) Biochem. Soc. Trans. 8, 205-213

Srere, P. A. \& Foster, D. W. (1967) Biochem. Biophys. Res. Commun. 26, 556-561

Srere, P. A. \& Henslee, J. G. (1980) in Cell Compartmentation and Metabolic Channelling (Nover, L., Lynen, F. \& Mothes, K., eds.), pp. 159-169, Gustav Fischer Verlag, Jena, and Elsevier, Amsterdam

Stoner, H. B. \& Marshall, H. W. (1971) Br. J. Exp. Pathol. 52, 650-655

Tischler, M. E., Hecht, P. \& Williamson, J. R. (1977) Arch. Biochem. Biophys. 181, 278-292

Veech, R. L., Eggleston, L. V. \& Krebs, H. A. (1969) Biochem. J. 115, 609-619

von Korff, R. W. (1960) Methods Enzymol. 13, 425-430

Walsh, G. M., Ferrone, R. A., Tsuchiya, M., Woods, E. F. \& Deland, E. C. (1980) Am. J. Physiol. 239, H805-H809

Wang, M.-S. \& Kurokawa, K. (1984) Am. J. Physiol. 246, F59-F66

Williamson, J. R., Scholz, R. \& Browning, E. T. (1969) J. Biol. Chem. 244, 4617-4627

Vol. 227 